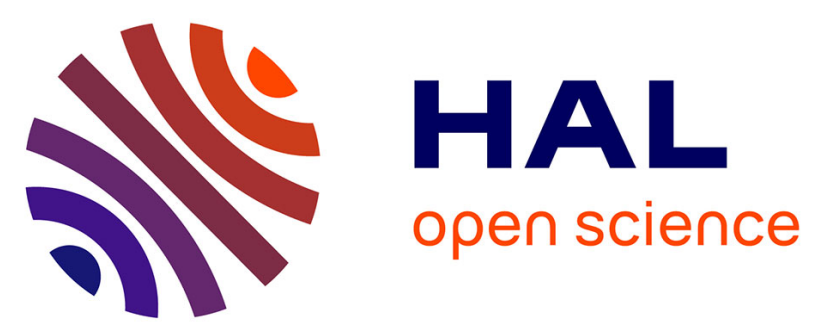

\title{
Intrapleural Photodynamic Therapy for Mesothelioma: What Place and Which Future?
}

Camille Munck, S. Mordon, Arnaud Sherpereel, Henri Porte, Xavier Dhalluin, Nacim Betrouni

\section{- To cite this version:}

Camille Munck, S. Mordon, Arnaud Sherpereel, Henri Porte, Xavier Dhalluin, et al.. Intrapleural Photodynamic Therapy for Mesothelioma: What Place and Which Future? Proceedings of the American Thoracic Society, 2015, pp.2237/45. hal-01183299

\section{HAL Id: hal-01183299 \\ https://hal.science/hal-01183299}

Submitted on 2 Sep 2015

HAL is a multi-disciplinary open access archive for the deposit and dissemination of scientific research documents, whether they are published or not. The documents may come from teaching and research institutions in France or abroad, or from public or private research centers.
L'archive ouverte pluridisciplinaire HAL, est destinée au dépôt et à la diffusion de documents scientifiques de niveau recherche, publiés ou non, émanant des établissements d'enseignement et de recherche français ou étrangers, des laboratoires publics ou privés. 
Intrapleural photodynamic therapy for mesothelioma: what place and which future?

Camille Munck ${ }^{1}$, Serge R. Mordon, $\mathrm{PhD}^{1}$, Arnaud Scherpereel, $\mathrm{MD}^{2}, \mathrm{PhD}$, Henri Porte, $\mathrm{MD}^{3}$, PhD, Xavier Dhalluin ${ }^{2}, \mathrm{MD}$, Nacim Betrouni, $\mathrm{PhD}^{1}$

${ }^{1}$ INSERM, U703, 152, rue du Dr. Yersin, 59120 LOOS, France

${ }^{2}$ Department of Pulmonary and Thoracic Oncology, Calmette Hospital, Lille, France

${ }^{3}$ Department of Thoracic Surgery, Calmette Hospital, Lille, France

\section{Keys words}

Mesothelioma, Radiation therapy, Clinical trials, Pleura

\section{Word count: 6496}

\section{Corresponding author}

Nacim Betrouni, INSERM U703,152,rue du Dr. Yersin,59120,LOOS,France

Telephone number:+33 320446 722, fax number:+33 320446738

E-mail:nacim.betrouni@inserm.fr 


\section{ABSTRACT}

In the surgical multimodal management of malignant pleural mesothelioma (MPM), it seems crucial to proceed with an efficient local adjuvant treatment to kill residual tumor cells. Recently, intrapleural photodynamic therapy (PDT) has emerged as a potential candidate in this goal. In this review, we analyzed and classified 16 articles in which patients with MPM underwent PDT after maximal surgical resection. The toxicity, impact on survival and development of the technique were assessed. After two decades of clinical studies, intrapleural PDT after surgery became a safe treatment which significantly improved the survival of patients.

Word count: 93 words 


\section{INTRODUCTION}

Malignant pleural mesothelioma (MPM) is an aggressive serosal tumor of the pleura. Its main aetiological agent is an exposure to asbestos fibers, mostly work-related, and the disease appears after a latency of 30 to 40 years after initial exposure. MPM is considered as a rare tumor. However, its incidence is rising throughout the world because of the increasing use of asbestos until the 1970's and will peak in the next decade. We also fear a pandemic rise of MPM in the future with developing countries still using asbestos today. The three main histologic subtypes of MPM are epithelial, biphasic and sarcomatoïd. MPM has a poor prognosis with a median survival of less than a year. This can be explained by the delay of diagnosis due to late clinical symptoms, with a disease already advanced locally, the difficulty of obtaining a confident anatomopathological diagnosis, and a complex treatment with deceiving outcomes.

\section{Current treatments for malignant pleural mesothelioma}

Treating MPM remains a challenge and there are two main alternatives: palliative chemotherapy or multimodal treatment including surgery, combined with chemotherapy and/or radiotherapy [1]. Surgery offers the best chance of survival and surgical cytoreduction should be performed when macroscopic complete resection is deemed achievable [2]. However, after the most complete tumor resection, microscopic tumor cells persist and surgery should be associated with a local adjuvant treatment. There are two leading types of surgery for the treatment of MPM: extrapleural pneumonectomy (EPP) and pleurectomy/decortication (P/D) or radical pleurectomy. EPP consists of an "en bloc" resection of the lung, visceral and parietal pleura, pericardium and diaphragm whereas P/D preserves the lung and is therefore less disabling. A modified EPP attempts to preserve the barriers of the peritoneum, pericardium, abdomen and phrenic nerve to the diaphragm. P/D is defined by the resection of the visceral and parietal pleura, and is referred to "extended 
P/D" when the pericardium and/or the diaphragm are resected [3]. Pleurectomy associated with a lobectomy $(\mathrm{P} / \mathrm{L})$ is also a possibility.

Even after optimal surgery and perioperative chemo-radiotherapy, local or distant recurrences are inevitable. In order to kill the residual microscopic disease, many teams have worked on intrapleural therapies like hyperthermic cisplatin-based chemotherapy, immunotherapy or genotherapy [4]. In search of a more effective and selective adjuvant treatment to surgery, and in line with these intrapleural therapies, intra-operative photodynamic therapy (PDT) could be of interest in part of a multimodal treatment for MPM.

\section{Photodynamic therapy}

PDT became acknowledged as an innovative oncological treatment in the 1970's by Dougherty et al. [5]. The effect of PDT requires the interaction of 3 components: a photosensitizer (PS), oxygen and light with the specific wavelength activating the PS. None of them are individually toxic but when put together they induce a tumoricidal photochemical reaction (Figure 1). The PS used in the treatment of MPM are porfimer sodium Photofrin ${ }^{\circledR}$ and m-tetrahydroxyphenylchlorin (m-THPC) Foscan®. The effect of PDT depends on the type and dose of PS used, the light dose and the oxygen concentration in the tissue illuminated. The appeal of PDT as an adjuvant treatment relies on its relative tumor selectivity, depending on a PS able to direct itself and stay longer in the tumor cells than in the normal cells, and an illumination restricted to the cancer superficial zone. Intrapleural PDT is based on a two-stage process: 1) intravenous administration of the photosensitizer before surgery with a specific drug dose and drug-light interval (DLI), 2) intraoperative illumination of the pleural cavity, after maximal resection of the tumor, by a laser source at an appropriate wavelength, and reaching a specific light dose $\left(\mathrm{J} / \mathrm{cm}^{2}\right)$.

MPM is essentially confined to the hemithorax at diagnosis, which would make an efficient surgical treatment all the more valuable. PDT is a preoperative local treatment, used successfully in other medical fields, so it seems legitimate to consider intrapleural PDT as a 
valid candidate to eradicate the microscopic tumor cells remaining after surgical resection. For a few decades, photodynamic therapy has been the subject of many studies as part of a multimodal treatment of malignant pleural mesothelioma with surgery. A review by Moghissi and Dixon [6] reported the results of ten of these studies, published between 1994 and 2004. It considered PDT as a treatment with potential but needing further improvement and clinical investigation. The aim of this review is to get a wider overview of this developing technique from its early days up to the present day, by exposing its various clinical applications in the surgical management of MPM, as well as its evolution through the years regarding toxicity and impact on survival.

\section{$\underline{\text { METHODS }}$}

Articles were researched on Pubmed, EM-premium and ScienceDirect, using the key words "malignant pleural mesothelioma", "pleural malignancies", "photodynamic therapy", "multimodal treatment", "surgery", "pneumonectomy" and "pleurectomy". The inclusion criteria were clinical studies focusing only on intrapleural photodynamic therapy after surgical resection, studies with results on the toxicity or survival of this treatment, articles written in English. Exclusion criteria were letters, editorials or case reports, experimental studies on animals, studies without enough specific data on PDT or surgical treatment. These studies were classified between two categories: "feasibility and toxicity studies" and "survival studies". Further research was made when general information was considered useful to the reader.

\section{RESULTS}

Sixteen articles published between 1991 and 2012 were selected for this review and are reported in Table 1. Eleven studies were described as "feasibility and toxicity studies" and 
aimed at finding the most optimal dose of PS, DLI and light dose. Five studies were classified as "survival studies" among which two phase III studies and three retrospective studies with a focus on survival. A total of 337 patients were included in these studies. Treatment consisted of a debulking surgery of variable degree, after administration of either m-THPC (20\% of patients) or a hematoporphyrin, ( $80 \%$ of patients) and followed by intraoperative PDT. Surgical treatment consisted of EPP, P/L and P/D for respectively $41,5 \%, 5 \%$ and $53,5 \%$ of patients. All causes of morbidity and mortality encountered in these studies during thoracic surgery and intrapleural PDT are listed in Table 2.

\section{Feasibility and toxicity studies}

Between 1991 and 2001, a Swiss and Dutch team published 4 studies [7-10] using m-THPC Foscan ${ }^{\circledR}$ and a light at a $650 \mathrm{~nm}$ wavelength. The first study [7] included four patients with MPM. Preliminary PDT was performed in 2 patients under different PDT conditions, and biopsies of tumor were taken after 5 days. A 10-mm-deep tumor necrosis was observed at a Foscan® drug dose of $0.3 \mathrm{mg} / \mathrm{kg}$, given 2 days before PDT and at a light dose of $10 \mathrm{~J} / \mathrm{cm}^{2}$. Surgery and intraoperative PDT were then performed: light was delivered through a bare optical fiber directly into the cavity at a light dose of $10 \mathrm{~J} / \mathrm{cm}^{2}$ to the diaphragm and costophrenic sulcus. A dose of $5 \mathrm{~J} / \mathrm{cm}^{2}$ was applied to the rest of the cavity. One patient died of aspiration pneumonia: autopsy revealed a PDT-induced necrosis of the remaining tumor.

In the second study [8], the same cohort was expanded to 7 patients. PDT followed the same protocol, except that DLI was either 2 or 3 days. No photosensitivity was observed after mTHPC administration of $0.1 \mathrm{mg} / \mathrm{kg}$, whereas at the dose of $0,3 \mathrm{mg} / \mathrm{kg}$, skin photosensitivity lasted up to two and half weeks. There was a severe skin necrosis after exposure to bright light 24 hours after m-THPC administration. One patient developed a colonic perforation, with PDT induced necrosis on the resection, and another patient developed a bronchopleural fistula. 
In the next study [9], four patients with MPM were given $0.1 \mathrm{mg} / \mathrm{kg}$ of Foscan® 4 days prior to surgery. The surgical objective was to obtain a macroscopic complete resection. The light was delivered at a dose of $10 \mathrm{~J} / \mathrm{cm}^{2}$. The pleural cavity was illuminated with a spherical diffusing fiber. A sterile plastic bag filled with saline was placed in the chest cavity. Four isotropic probes were placed inside intrathoracic strategic locations to monitor the light distribution. Illumination was adapted to reach the total dose of $10 \mathrm{~J} / \mathrm{cm}^{2}$, according to the real-time dosimetry. Biopsies of remaining tumor and normal tissue were taken 24 hours after treatment under thoracoscopy. They showed an increase in inflammatory cells and oedema in the tumor samples and less damage in the normal tissue. There was no postoperative mortality and postoperative complications were a diaphragmatic rupture and a hemopericardium.

In a larger phase I and II study of 26 patients, Schouwink et al [10] evaluated the toxicity of mTHPC PDT at different drug doses and DLI. Among them, 4 patients had already been included in the previous study [9]. The mTHPC concentrations were 0,075, 0,1 and $0,15 \mathrm{mg} / \mathrm{kg}$ with a DLI of 4 days, and $0.15 \mathrm{mg} / \mathrm{kg}$ with a DLI of 6 days, forming four groups of 4 patients each for the phase I part of the study. PDT protocol was the same as previously described [9]. The two groups receiving $0,15 \mathrm{mg} / \mathrm{kg}$ of $\mathrm{mTHPC}$ were stopped prematurely because of a death in each group (a myocardial infarction and an empyema secondary to a bronchopleural fistula). Therefore, the maximum tolerated dose of mTHPC was $0,1 \mathrm{mg} / \mathrm{kg}$ with illumination after four days. The group of patients with this drug dose was expanded to a total of 19 patients for the phase II part of the study. Real-time dosimetry led to additional illumination to reach the expected dose of $10 \mathrm{~J} / \mathrm{cm}^{2}$ at the four sites in 12 patients out of the 26. Complications were a spinal cord infarction secondary to a myocardial infarction and skin burns, in the $0.15 \mathrm{mg} / \mathrm{kg}$ dose group. In the $0,1 \mathrm{mg} / \mathrm{kg}$ mTHPC group, a third patient died of an oesophageal fistula related to excessive illumination of the oesophageal and heart region.

Another phase I study [11] using Foscan® was conducted by Friedberg et al.: 26 patients with MPM underwent EPP or $\mathrm{P} / \mathrm{D}$, after receiving $0,1 \mathrm{mg} / \mathrm{kg}$ of Foscan®. Patients were 
divided into 4 groups with DLI of 4 or 6 days, and light doses of 5 or $10 \mathrm{~J} / \mathrm{cm}^{2}$. Illumination was performed with a spherical diffusing fiber placed in the centre of a plastic bag filled with saline, described earlier. For some patients, an end-cut fiber set in a modified endotracheal tube was moved around the pleural cavity, in dilute intralipid solution. Light delivery was monitored by four isotropic probes. At the first dose level, one patient had a third-degree burn requiring a skingraft, two patients died of a septic shock due to pneumonia and a malignant hyperthermia. The maximal tolerated dose of PDT was determined as a Foscan® administration of $0,1 \mathrm{mg} / \mathrm{kg}, 6$ days before illumination, at $10 \mathrm{~J} / \mathrm{cm}^{2}$, after 2 patients died of a systemic capillary leak syndrome. At this dose level, 14 more patients were treated without significant complications.

Pass et al. [12] reported a large study of 42 patients with pleural malignancies, among which were 31 MPM. The surgical objective was to obtain a macroscopic complete resection. After administration of Photofrin® $(2 \mathrm{mg} / \mathrm{kg})$, light was delivered by an optical fiber passed through a modified endotracheal tube, with dilute intralipid in the cuff and the pleural cavity. Seven photodiodes were placed inside the thoracic cavity at strategic locations, and permitted realtime dosimetry. The first 33 patients were given Photofrin ${ }^{\circledR} 48$ hours before surgery, and the last 9 patients, 24 hours before. In the first group, light dose was escalated from $15 \mathrm{~J} / \mathrm{cm}^{2}$ to $35 \mathrm{~J} / \mathrm{cm}^{2}$, with levels of $2.5 \mathrm{~J} / \mathrm{cm}^{2}$, and in the group of 24 hours DLI, light dose was $30 \mathrm{~J} / \mathrm{cm}^{2}$ and $32.5 \mathrm{~J} / \mathrm{cm}^{2}$. Regarding possible PDT-induced complications, one patient died of an empyema associated with a massive haemorrhage of the right atrium. Two patients developed a bronchopleural fistula at the 17.5 and $35 \mathrm{~J} / \mathrm{cm}^{2}$ level (DLI of 48 hours). Two patients had a low oesophageal necrosis and perforation after a DLI of 24 hours and a light dose of $32.5 \mathrm{~J} / \mathrm{cm}^{2}$. The maximum tolerated dose was declared as $2 \mathrm{mg} / \mathrm{kg}$ of Photofrinß given 24 hours before illumination, at a light dose of $30 \mathrm{~J} / \mathrm{cm}^{2}$.

Warloe et al. [13] described their experience with 9 patients who were given $2 \mathrm{mg} / \mathrm{kg}$ of Photofrin 48 hours prior to surgery. Light at $630 \mathrm{~nm}$ was delivered at a dose of $15 \mathrm{~J} / \mathrm{cm}^{2}(1$ patient), $20 \mathrm{~J} / \mathrm{cm}^{2}$ (3 patients) and $30 \mathrm{~J} / \mathrm{cm}^{2}$ (5 patients). There was no postoperative mortality. 
There was a case of persisting leakage from a thoracic lymphatic vessel, one of localized skin necrosis near the thoracotomy, and one pulmonary infection.

Takita et al. [14] presented a study in which 23 patients received $2 \mathrm{mg} / \mathrm{kg}$ of Photofrin® 2 days before surgery: six EPP, fifteen P/D and two unresectable tumour (no PDT). The surface area of the hemithorax to be treated was determined by reconstruction of a life-size thorax model from the patient's chest CT scan. Four bulb optical fibers were placed centrally in the thorax model at equidistance and light dose measurements were made. Illumination at $630 \mathrm{~nm}$ was delivered at a dose of $20 \mathrm{~J} / \mathrm{cm}^{2}$ for the first 7 patients and $25 \mathrm{~J} / \mathrm{cm}^{2}$ for the others, with the optical fibers located according to the planning of the thorax model. Postoperative morbidity was found in more than half of the patients. One patient died of an empyema and bronchopleural fistula, and another of pulmonary infection.

In a second study, Takita et al. [15] continued to include up to 31 patients with the same PDT protocol except that the light dose was increased: 7 patients had already received $20 \mathrm{~J} / \mathrm{cm}^{2}$, 21 patients received $25 \mathrm{~J} / \mathrm{cm}^{2}$ and 3 patients received $30 \mathrm{~J} / \mathrm{cm}^{2}$. No additional postoperative mortality was observed.

The same team continued to include patients into this phase II study with the same light doses of 20,25 and $30 \mathrm{~J} / \mathrm{cm}^{2}$, and reported a 6-year follow-up of 40 patients [16] . All in all, there were three postoperative deaths due to bronchopleural fistulas and empyema. Post operative complications were found for $45 \%$ of the patients: bronchopleural fistula, empyema, splenic rupture, diaphragmatic dehiscence or hemorraghe, and oesophageal perforation.

In a study of 11 patients, Du et al. [17] described their experience with intensity modulated radiation therapy after EPP with PDT (7 patients) or without (4 patients). Photofrin® $(2 \mathrm{mg} / \mathrm{kg})$ was given 24 hours before surgery and light at $630 \mathrm{~nm}$ was delivered at $60 \mathrm{~J} / \mathrm{cm}^{2}$. One patient had a radiation pneumonitis. Multimodal treatment by EPP, radiation and PDT was deemed feasible by the authors, with acceptable toxicity. 


\section{Survival studies}

The first phase III trial was conducted by Pass et al. [18]: 25 patients underwent surgery with PDT and 23 patients without PDT, along with postoperative immune-chemotherapy. The PDT group was given Photofrin® 24 hours prior to surgery. Light was delivered through the endotracheal tube, as described previously [12], at a dose of $30 \mathrm{~J} / \mathrm{cm}^{2}$. Light dosimetry was carried out by 7 photodiodes in the chest cavity. There was one perioperative death in the PDT group due to an inferior vena cava avulsion, and there were 2 bronchopleural fistulas in each group. There was no significant difference between the PDT and no-PDT group in median OS: respectively 14,4 months and 14,1 months, or median DFS: respectively 8,5 months and 7,7 months.

A second phase III study by Matzi et al. [19] evaluated the feasibility and the influence on survival of intrapleural PDT under hyperbaric hyperoxygenation. 34 patients underwent a P/D, 22 of them received additional PDT, and 12 of them did not. For the PDT group, Photosan®, a poly-hematoporphyrin, was given 48 hours prior to surgery performed in a hyperbaric chamber equipped as an operating room. Light was delivered through a microlens, at the dose of $300 \mathrm{~J}$ with a distance of $1 \mathrm{~cm}$ from the tumor surface. There was no light dosimetry but a transcutaneous pO2-levels monitoring under hyperbaric oxygenation. The median survival for the PDT group versus the no-PDT group was respectively 15 months and 10 months $(p=0.0179)$. After a 6 months follow-up, local tumor recurrence was lower in the PDT group (9/22 patients) compared to the no-PDT group (10/12 patients). There was no major complication related to PDT or hyperbaric oxygenation.

PDT for MPM was also performed in a retrospective study [20] evaluating the efficacy of multimodal treatment including various types of treatment options (surgical and non surgical). Among the 44 patients undergoing surgery, 20 patients received intraoperative PDT combined with P/D for 17 patients and EPP for 3 patients. Photofrin® was injected 48 hours 
prior to surgery and the pleural cavity was illuminated using a laser delivering a light through a microlens, applied close to the intrathoracic surfaces. This study indicated that, when considering only the patients who had P/D, neither intraoperative PDT or additional chemotherapy or radiotherapy, had any significant impact on survival.

Friedberg et al. [21] published a retrospective study about 28 patients with MPM undergoing surgery, 14 by modified EPP and 14 by P/D, and intraoperative PDT. Neoadjuvant and adjuvant treatment was pemetrexed-based chemotherapy or hemithoracic radiotherapy, but was not standardized. Photofrin $\AA$ was injected 24 hours before surgery. Light was delivered through a laser fiber set in an endotracheal tube with a cuff filled with dilute intralipid and moved inside the pleural cavity, also filled with dilute intralipid. The light dose threshold was set at $60 \mathrm{~J} / \mathrm{cm}^{2}$ and measured by seven isotropic probes placed in strategic intrathoracic locations, allowing real-time dosimetry. Both groups had $85,7 \%$ of patients with a stage III or IV. Two postoperative deaths occurred in the modified EEP group, due to a stroke and aspiration pneumonia. The median OS for the group modified EPP and P/D was respectively 0,7 year and unreached after a follow-up of 2,1 years $(p=0.009)$. The DFS between the group modified EPP and P/D was respectively 0.6 year and 1,9 years $(p=0.15)$. When analysing the epithelial histologic subgroups, there was a significant difference $(p=0.0001)$ in the median OS in favour of the P/D group (unreached) compared to the modified EPP group (0.4 year).

Given these results, Friedberg et al. stopped performing modified EPP and extended their cohort of patients undergoing a lung-sparing procedure [22]: 38 patients were treated by P/D and PDT, with postoperative chemotherapy for 35/38 patients. PDT followed the same protocol as described above. 37 out of 38 patients had a stage III and IV MPM. Macroscopic complete resection was obtained in $37 / 38$ patients. At a median follow up of 34,4 months, the median OS was 31,7 months (95\% [Cl] 9-54,3 months) and the median DFS was 9,6 months (95\% [CI] 6,8-12,4 months). The median OS and DFS of patients with epithelial subtype were respectively 41,2 months $(95 \%$ [Cl] 25,9-56,4 months) and 15,1 months (95\% [Cl] 0,8-29,3 months). 


\section{DISCUSSION}

These sixteen studies were very heterogeneous when considering the size of cohorts, the stage and histologic subtype of the MPM, the type of surgery and thickness of tumour resection, adjuvant treatment and the PDT technique. Given that, it was difficult to compare them statistically and sort out the specific toxicity of intrapleural PDT and its impact on survival.

\section{Toxicity}

Distinction between surgical and PDT-related toxicity was not possible to establish since most of these articles studied only patients receiving intrapleural PDT after surgery. The two phase III clinical trials $[18,19]$ did not observe a difference in complications in the group PDT versus no-PDT, however the small size of their cohorts did not allow to point out specific side effects of intrapleural PDT. Analysis of the PDT-toxicity is also biased by the toxicity induced by each type of surgery. It could be divided into known specific toxicity (photosensitivity), probable specific toxicity (PDT-induced necrosis of tissue after illumination) and uncertain toxicity (mixed with surgical complications).

With clinical experience, photosensitivity decreased in severity as well as in frequency. Aside from the patient's strict light eviction after PS administration before and after surgery, other measures were progressively taken. The operating room lights were covered by surgical drapes, then by yellow filter papers, blue towels were sown to the incision skin edges to avoid unwanted illumination, the pulse oxymeter was rotated between fingers to prevent nail burns [11].

Intrapleural PDT combined with thoracic surgery is associated with a non negligible toxicity, at least at its beginning. In the early studies, histologic analysis of treated tissue showed that PDT induces a certain degree of necrosis [7-9]. When the biopsy of the complication site or autopsy showed tissue necrosis, PDT was logically linked to the corresponding complication: an oesophageal fistula [10], a colonic perforation [7] and low oesophageal perforation for two 
patients [12]. It was also associated with systemic capillary leaking syndrome for two patients [11], haemorrhage of the right atrium [12], causing the death of these patients. This was supported by the fact that the team admitted to excessive illumination at the location of the complication. Toxicity was clearly correlated with the PS drug concentrations and light doses. The maximum tolerated dose was for Foscan® $0.1 \mathrm{mg} / \mathrm{kg}$ given 4 days [10] or 6 days [11] before illumination with a light dose of $10 \mathrm{~J} / \mathrm{cm}^{2}$, and for Photofrin $\circledast 2 \mathrm{mg} / \mathrm{kg}$ given 24 hours before illumination at a light dose of $30 \mathrm{~J} / \mathrm{cm}^{2}[12]$ or $60 \mathrm{~J} / \mathrm{cm}^{2}$ in the studies of Friedberg et al. $[21,22]$, even if they are not phase II clinical trials. Friedberg et al. [22] noted more respiratory insufficiency requiring reintubation with PDT, possibly resulting from the systemic inflammatory response associated with PDT. The evolution was favourable in less than a week. Nevertheless, given the results of Friedberg's studies, we can assume that when patients are preoperatively carefully selected, and when light delivery is monitored, toxicity to adjacent organs like the heart, vessels or oesophagus, is limited.

Apart from Photofrin $\AA$, Foscan $\AA$ is the only other PS approved for use in systemic cancer therapy. Foscan $\AA$ is known to have a much higher tumour toxicity than Photofrin $\circledast$, however clinical studies have demonstrated that this better efficacy can also induce higher complications. Moghissi and Dixon [6] compared data from 10 papers [8-12,14-16,18,19] with 230 patients (170 with Photofrin $\AA$, 60 with Foscan $\AA$ ). They calculated an overall mortality of $4.9 \%$ for Photofrin $\AA$ and $13.3 \%$ for Foscan $\AA$, and morbidity was respectively $38 \%$ and $70 \%$. Consequently, Photofrin ${ }^{\circledR}$ is now preferred for the treatment of MPM.

\section{PDT technique}

The technique of intrapleural PDT has improved throughout the years of practice, certainly playing a role in the better tolerance of the treatment. For starters, the "tools" used to deliver the light in the thoracic cavity have evolved from a simple bare fiber or microlens to a spherical or cylindrical fiber moved within the cavity, until the fiber was put in a modified 
endotracheal tube to facilitate the movement of the light source. The complex geometry of the thoracic cavity, with or without a remaining lung, has raised many issues regarding the uniformity of light delivery. To increase the light diffusion, two teams used a sterile plastic bag filled with saline placed in the cavity in which an optical fiber was moved $[9,12]$. Friedberg et al. filled the cuff of this endotracheal tube with dilute intralipid as well as the pleural cavity. In addition, the emergence of high power lasers allowed to considerably shorten the length of illumination, which is valuable especially when light dose for Photofrin ${ }^{\circledR}$ was increased from $15 \mathrm{~J} / \mathrm{cm}^{2}[12,13]$ to $60 \mathrm{~J} / \mathrm{cm}^{2}[21,22]$ in a decade.

Considering the empiric illumination of the pleural cavity, a light delivery monitoring became necessary: four isotropic probes $[9,10]$, then seven probes $[12,18,21,22]$ were sown to strategic locations, prone to be under-exposed. The probes were connected to a dosimetry system which gave a real-time feedback of the light fluence so that the light delivered could be adjusted. This seven-probes dosimetry system was further explored by the team of Dimofte and Zhu, along with the correlation between the volume and surface area of the pleural cavity and the treatment time $[23,24]$.

After acting on PS and light conditions, only one study focused on tissue oxygenation, where 22 patients underwent surgery in a hyperbaric chamber. Matzi et al. [19] proved that performing PDT in this technically complex environment was feasible, but we can understand how it cannot be logistically displayed in any medical facility. Since every patient underwent surgery under hyperbaric oxygenation, the specific effect of this technique couldn't be singled out.

\section{Survival}

The preliminary studies did not show a beneficial impact of intrapleural PDT on survival for patients undergoing surgery: when specified [10,12,14-16], median OS did not exceed 15 months (Table 1) and PDT seemed beneficial only for stage I and II MPM with a median OS of 21 months [15] and 36 months [16]. 
The first phase III clinical trial [18] was a well-conducted study with comparable groups regarding the population, the extent of the MPM and associated treatments. There was no significant difference between the two groups in median OS, median DFS or recurrence patterns, but this study did not include enough patients to reach its statistical power. Another phase III trial [19] explored the benefit of adding hyperbaric oxygenation to P/D and intraoperative PDT. Even with less patients than the previous study, a significant difference was found regarding median OS $(p=0,0179)$ in favour of PDT, with the advantage of having the same surgery (P/D) in each arm. These engaging results were a result of a lung-sparing procedure. At the beginning of surgical for MPM, EPP was preferred to P/D because it would guarantee less microscopic tumour residue. There are no randomized clinical trials comparing lung-sacrificing surgeries to lung-sparing ones, however recent studies have supported P/D over EPP [25-27]. A prospective non randomized study [26] of 25 EPP and $61 \mathrm{P} / \mathrm{D}$, as part of a multimodal treatment, showed a significant difference $(p=0.004)$ in median OS between the EPP group (12,8 months) and the P/D group (23 months). With PDT as a local adjuvant treatment, two retrospective studies by Friedberg et al. [21,22] also pointed out the advantage of a lung-sparing surgical procedure. In the first one, two comparable groups of 14 patients underwent MEPP and P/D with an objective of complete macroscopic resection. The median OS was greatly superior for the P/D group $(p=0,009)$.Their second study with only P/D surgery comforted these results with a remarkable survival of 31,7 months (95\% [Cl] 9-54,3 months), and with a majority of very advanced disease. This is all the more impressive when you compare the median OS of patients who received P/D without PDT at a stage III and IV, which are respectively 13 and 9 months [25]. Whereas the studies of Takita and Moskal showed a clear advantage of PDT for patients with stage I and II MPM in terms of survival, Friedberg et al. showed that P/D with intrapleural PDT had a beneficial impact, regardless of the advanced stage or bulkiness of the tumour, if macroscopic resection was achieved. However optimistic these results might be, they are under the provision of retrospective non-randomized studies, small-sized cohorts, and unstandardized adjuvant treatments. 
Patients with an epithelial histological subtype usually have a better outcome. In a study of 183 patients undergoing EPP, Sugarbaker et al. [28] reported a 2 and 5-year survival rate of $52 \%$ and $21 \%$ for the epithelial subtype, and of $16 \%$ and $0 \%$ for the non-epithelial subtype. This was confirmed for surgical treatment with intrapleural PDT $[16,21,22]$ with significant survival difference. It can raise the question of a strict histological selection of patients for this technique.

Although P/D leads to a less complete resection of tumor cells, median OS in P/D patients was much longer than the one observed in MEPP patients [21]. However, the recurrence rate of P/D patients was higher and there was no difference in DFS between the two groups. This could be explained by recurrences being better tolerated with two lungs, along with a better quality of life. It is now accepted that PDT can result in the generation of anti-tumour inflammatory cells and can lead to a persistent anti-tumour immune response [29]. Therefore, a PDT-induced immune response against the remaining malignant cells could result in more indolent recurrence patterns.

The outstanding survival observed in these two recent studies could be explained by a better preoperative staging and selection of patients regarding respectability and a more complete and homogeneous light delivery with dosimetry to the best of its performance.

\section{CONCLUSION}

When a surgical treatment is considered for MPM, it should be part of a multimodal arsenal aiming to kill all residual microscopic tumour cells. After two decades of inconclusive results, intrapleural PDT has evolved to be a feasible technique, with minimum toxicity. In the absence of an efficient treatment, it presents itself as good alternative among other local adjuvant treatments to surgery. Indeed, two recent studies [21,22] have demonstrated that 
Photofrin®-mediated PDT, after complete macroscopic resection, offers a remarkable survival even in patients with locally advanced stages of MPM, especially with an epithelial histologic subtype and when a lung-sparing procedure is performed. A randomized phase II trial with or without Photofrin®-mediated PDT is ongoing at the moment at the University of Pennsylvania (Philadelphia, USA) and Roswell Park (Buffalo, USA). Today, every effort should be made to improve the illumination and dosimetry technique, since the success of PDT closely depends on a complete and homogeneous light delivery. In this spirit, scientists are leaning towards computer-assisted procedures, such as an infra-red navigation system to track the movement of the light source within the pleural cavity in real-time [30]. The objective is to get a feedback of the light delivered on the whole pleural surface and adapt illumination accordingly. Research teams are also turning towards new illumination devices, like a light blanket made of optical fibers or textile light diffuser [31] which could be directly applied on the pleural surface, with the advantage of being flexible and bending along a complex geometrical cavity. Developing the technique of intrapleural PDT will be all the more beneficial since PDT can also be used to treat other pleural malignancies, such as the pleural metastasis of non-small cell lung cancer, and this with interesting results [32].

\section{Conflicts of interest}

The authors declare no conflict of interest.

\section{Acknowledgments}

This work was partially supported by a grant from the Société de Pathologie Thoracique du Nord. 


\section{REFERENCES}

[1] Scherpereel A, Astoul P, Baas P. Guidelines of the European Respiratory Society and the European Society of Thoracic Surgeons for the management of malignant pleural mesothelioma. Eur Respir J 2009;35:479-95.

[2] Rusch V, Baldini E H, Bueno R et al. The role of surgical cytoreduction in the treatment of malignant pleural mesothelioma: Meeting summary of the International Mesothelioma Interest Group Congress. J Thorac Cardiovasc Surg, 2012;145:909-910

[3] Rice D. Surgery for malignant pleural mesothelioma. Ann Diagn Pathol 2009;13:65-72.

[4] Tsao AS, Mehran R, Roth JA. Neoadjuvant and Intrapleural Therapies for Malignant Pleural Mesothelioma. Clin Lung Cancer 2009;10:36-41.

[5] Dougherty TJ, Kaufman JE, Goldfarb A, Weishaupt KR, Boyle D, Mittleman A. Photoradiation therapy for the treatment of malignant tumors. Cancer Res 1978;38:2628-35.

[6] Moghissi K, Dixon K. Photodynamic therapy in the management of malignant pleural mesothelioma: A review. Photodiagnosis Photodyn Ther 2005;2:135-47.

[7] Ris HB, Altermatt HJ, Inderbitzi R et al. Photodynamic therapy with chlorins for diffuse malignant mesothelioma: initial clinical results. Br J Cancer 1991;64:1116-20.

[8] Ris HB, Altermatt HJ, Nachbur B et al. Intraoperative Photodynamic Therapy With mTetrahydroxyphenylchlorin for Chest Malignancies. Lasers Surg Med 1996;18:39-45.

[9] Baas P, Murrer L, Zoetmulder FA. Photodynamic therapy as adjuvant therapy in surgically treated pleural malignancies. Br J Cancer 1997;76:819.

[10] Schouwink H. Intraoperative Photodynamic Therapy After Pleuropneumonectomy in Patients With Malignant Pleural Mesothelioma *: Dose Finding and Toxicity Results. CHEST J 2001;120:1167. 
[11] Friedberg JS, Mick R, Stevenson J. A phase I study of Foscan-mediated photodynamic therapy and surgery in patients with mesothelioma. Ann Thorac Surg 2003;75:952-9.

[12] Pass HI, DeLaney T, Tochner Z et al. Intrapleural Photodynamic Therapy: results of a Phase I Trial. Ann Surg Oncol 1994;1:28-37.

[13] Warloe T, Heyerdahl H, Peng Q. Photodynamic therapy of malignant mesothelioma of pleura. SPIE Proc 1995;2371.

[14] Takita H, Mang TS, Loewen GM. Operation and intracavitary photodynamic therapy for malignant pleural mesothelioma: A phase II study 2 . Ann Thorac Surg 1994;58:9958.

[15] Takita H, Dougherty TJ. Intracavitary photodynamic therapy for malignant pleural mesothelioma. Semin. Surg. Oncol., vol. 11, Wiley Online Library; 1995, p. 368-71.

[16] Moskal TL, Dougherty TJ, Urschel JD. Operation and photodynamic therapy for pleural mesothelioma: 6-year follow-up. Ann Thorac Surg 1998;66:1128-33.

[17] Du KL, Both S, Friedberg JS, Rengan R, Hahn SM, Cengel KA. Extrapleural pneumonectomy, photodynamic therapy and intensity modulated radiation therapy for the treatment of malignant pleural mesothelioma. Cancer Biol Ther 2010;10:425-9.

[18] Pass HI, Temeck BK, Kranda K et al. Phase III randomized trial of surgery with or without intraoperative photodynamic therapy and postoperative immunochemotherapy for malignant pleural mesothelioma. Ann Surg Oncol 1997;4:628-33.

[19] Matzi V, Maier A, Sankin O. Photodynamic therapy enhanced by hyperbaric oxygenation in palliation of malignant pleural mesothelioma: clinical experience. Photodiagnosis Photodyn Ther 2004;1:57-64.

[20] Lindenmann J, Matzi V, Neuboeck N. Multimodal therapy of malignant pleural mesothelioma: is the replacement of radical surgery imminent? Interact Cardiovasc Thorac Surg 2012;16:237-43. 
[21] Friedberg JS, Mick R, Culligan M. Photodynamic Therapy and the Evolution of a LungSparing Surgical Treatment for Mesothelioma. Ann Thorac Surg 2011;91:1738-45.

[22] Friedberg JS, Culligan MJ, Mick R. Radical Pleurectomy and Intraoperative Photodynamic Therapy for Malignant Pleural Mesothelioma. Ann Thorac Surg 2012;93:1658-67.

[23] Dimofte A, Zhu TC, Jarod C. Finlay. In vivo light dosimetry for pleural PDT. In: Kessel DH, editor., 2009, p. 71640A-71640A-12.

[24] Zhu TC. Dosimetry in pleural photodynamic therapy. J Natl Compr Canc Netw 2012;10:S-60.

[25] Flores RM, Pass HI, Seshan VE. Extrapleural pneumonectomy versus pleurectomy/decortication in the surgical management of malignant pleural mesothelioma: Results in 663 patients. J Thorac Cardiovasc Surg 2008;135:620-626.e3.

[26] Lang-Lazdunski L, Bille A, Lal R et al. Pleurectomy/decortication is superior to extrapleural pneumonectomy in the multimodality management of patients with malignant pleural mesothelioma. J Thorac Oncol 2012;7:737-43.

[27] Cao C, Tian D, Park J, Allan J, Pataky KA, Yan TD. A systematic review and metaanalysis of surgical treatments for malignant pleural mesothelioma. Lung Cancer $2014 ; 83: 240-5$.

[28] Sugarbaker DJ, Flores RM, Jaklitsch MT et al. Resection margins, extrapleural nodal status, and cell type determine postoperative long-term survival in trimodality therapy of malignant pleural mesothelioma: results in 183 patients. J Thorac Cardiovasc Surg 1999;117:54-65.

[29] Castano AP, Mroz P, Hamblin MR. Photodynamic therapy and anti-tumour immunity. Nat Rev Cancer 2006;6:535-45. 
[30] Zhu TC, Liang X, Chang C et al. An IR navigation system for real-time treatment guidance of pleural PDT. In: Kessel DH, Hasan T, editors., 2011, p. 78860L-78860L-9.

[31] Cochrane C, Mordon SR, Lesage JC, Koncar V. New design of textile light diffusers for photodynamic therapy. Mater Sci Eng C 2013;33:1170-5.

[32] Friedberg JS. Phase II Trial of Pleural Photodynamic Therapy and Surgery for Patients With Non-Small-Cell Lung Cancer With Pleural Spread. J Clin Oncol 2004;22:2192201. 


\section{TABLES}

Table 1. Sixteen clinical studies on intrapleural photodynamic therapy for malignant pleural mesothelioma after surgical resection

\begin{tabular}{|c|c|c|c|c|c|c|c|c|c|c|c|c|c|}
\hline \multirow{2}{*}{$\begin{array}{l}\text { Study } \\
\text { (reference) }\end{array}$} & \multirow{2}{*}{ Year } & \multirow{2}{*}{ Phase } & \multirow{2}{*}{$\begin{array}{c}\text { Population } \\
\text { (number of patients) }\end{array}$} & \multirow{2}{*}{$\begin{array}{c}\text { Number of } \\
\text { patients with } \\
\text { MPM } \\
\end{array}$} & \multirow{2}{*}{ Photosensitizer } & \multirow{2}{*}{$\begin{array}{l}\text { Drug dose } \\
(\mathrm{mg} / \mathrm{kg})\end{array}$} & \multirow{2}{*}{$\begin{array}{c}\text { Dose light } \\
\text { interval } \\
\text { (day) }\end{array}$} & \multicolumn{3}{|c|}{ Surgical treatment } & \multirow{2}{*}{$\begin{array}{l}\text { Light dose } \\
\qquad\left(\mathrm{J} / \mathrm{cm}^{2}\right)\end{array}$} & \multirow{2}{*}{$\begin{array}{l}\text { Wavelength } \\
\text { (nm) }\end{array}$} & \multirow{2}{*}{$\begin{array}{c}\text { Median overall } \\
\text { survival (months) }\end{array}$} \\
\hline & & & & & & & & EPP & $\mathrm{P} / \mathrm{L}$ & $\mathrm{P} / \mathrm{D}$ & & & \\
\hline \multicolumn{14}{|c|}{ Feasibility studies } \\
\hline Ris (9) & 1991 & I & MPM (4) & 4 & Foscan® & 0,3 & 2 & 2 & 1 & 1 & $5-10$ & 650 & \\
\hline Baas (11) & 1997 & $\mathrm{I}$ & pleural malignancies (5) & 4 & Foscan® & 0,1 & 4 & 4 & & & 10 & 652 & \\
\hline \multirow{2}{*}{$\begin{array}{l}\text { Schouwink } \\
\text { (12) }\end{array}$} & \multirow{2}{*}{2001} & \multirow{2}{*}{$I-I I$} & \multirow{2}{*}{ MPM (26) } & \multirow{2}{*}{26} & \multirow{2}{*}{ Foscan® } & $0,075 / 0,1 / 0,15$ & 4 & \multirow{2}{*}{26} & & & \multirow{2}{*}{10} & \multirow{2}{*}{652} & \multirow{2}{*}{10} \\
\hline & & & & & & 0,15 & 6 & & & & & & \\
\hline Friedberg (13) & 2003 & $\mathrm{I}$ & MPM (26) & 26 & Foscan $\circledast$ & 0,1 & 4 and 6 & 7 & & 19 & $5-10$ & 652 & \\
\hline \multirow{2}{*}{ Pass (14) } & \multirow{2}{*}{1994} & \multirow{2}{*}{1} & \multirow{2}{*}{ pleural malignancies (42) } & \multirow{2}{*}{31} & \multirow{2}{*}{ Photofrin $\AA$} & \multirow{2}{*}{2} & 2 & 10 & 5 & 18 & 15 to 35 & 630 & 10 \\
\hline & & & & & & & 1 & 19 & 0 & 18 & $30-32,5$ & 630 & 10 \\
\hline Warloe (15) & 1995 & & MPM (9) & 9 & Photofrin® & 2 & 2 & 5 & 3 & 1 & $15-20-30$ & 630 & \\
\hline Takita (16) & 1994 & II & MPM (23) & 21 & Photofrin $\circledast$ & 2 & 2 & 6 & & 15 & $20-25$ & 630 & 12 \\
\hline Takita (17) & 1995 & II & MPM (31) & 29 & Photofrin $\AA$ & 2 & 2 & 6 & & 23 & $20-25-30$ & 630 & 12 \\
\hline Moskal (18) & 1998 & II & MPM (43) & 40 & Photofrin $\circledast$ & 2 & 2 & 28 & 5 & 7 & $20-25-30$ & 630 & 15 \\
\hline $\mathrm{Du}(19)$ & 2010 & & MPM (7) & 7 & Photofrin $\AA$ & 2 & 1 & 7 & & & 60 & 630 & \\
\hline Survival studies & & & & & & & & & & & & & \\
\hline Matzi (21) & 2004 & III & $\begin{array}{c}\text { MPM (34), PDT (20), } \\
\text { noPDT (12) }\end{array}$ & 22 & FotoSan® & 2 & 2 & & & 22 & $300^{*}$ & 630 & 15 (PDT) vs 10 (no PDT) \\
\hline $\begin{array}{l}\text { Lindenmann } \\
\text { (22) }\end{array}$ & 2012 & & MPM (20) & 20 & Photofrin ${ }^{\circledR}$ & 2 & 2 & 3 & & 17 & $300^{*}$ & 630 & \\
\hline Friedberg (23) & 2011 & & MPM & 28 & Photofrin $\AA$ & 2 & 1 & 14 & & 14 & 60 & 630 & $>25,2(\mathrm{P} / \mathrm{D})$ and 8,5 (EEP) \\
\hline Friedberg (24) & 2012 & & MPM & 38 & Photofrin ${ }^{\circledR}$ & 2 & 1 & & & 38 & 60 & 630 & 31,7 \\
\hline
\end{tabular}

A colour code brings together articles from the same scientific team. 
* $300 \mathrm{~J}$ with a distance of $1 \mathrm{~cm}$ using an optical fiber with a microlens

$\mathrm{MPM}=$ malignant pleural mesothelioma, $\mathrm{PDT}=$ photodynamic therapy, $\mathrm{EPP}=$ extrapleural pneumonectomy, $\mathrm{P} / \mathrm{L}=$ pleurectomy with lobectomy, $\mathrm{P} / \mathrm{D}=$ pleurectomy decortication 
Table 2. Toxicity related to surgery and intrapleural photodynamic therapy.

The number of patients concerned is indicated between brackets when possible

\begin{tabular}{|c|c|c|c|}
\hline \multicolumn{2}{|c|}{ Morbidity } & \multicolumn{2}{|c|}{ Mortality } \\
\hline Foscan® (59) & Photofrin $\AA$-Fotosan $\AA$ (206) & Foscan® (59) & Photofrin $\AA$-Fotosan $\AA$ (206) \\
\hline \multicolumn{4}{|c|}{ Thoracic } \\
\hline $\begin{array}{c}\text { Empyema (2) } \\
\text { Bronchopleural fistula (1) } \\
\text { Pneumonia (1) } \\
\text { Diaphragmatic rupture (3) } \\
\text { Diaphragmatic hemorrhage (3) }\end{array}$ & $\begin{array}{c}\text { Empyema (2) } \\
\text { Bronchopleural fistula (6) } \\
\text { Pneumonia (5) } \\
\text { Diaphragmatic rupture (1) }\end{array}$ & $\begin{array}{l}\text { Bronchopleural fistula (1) } \\
\text { Pneumonia (1) }\end{array}$ & $\begin{array}{c}\text { Empyema (1) } \\
\text { Bronchopleural fistula (2) } \\
\text { Pneumonia (2) }\end{array}$ \\
\hline \multicolumn{4}{|c|}{ Cardiovascular } \\
\hline $\begin{array}{l}\text { Myocardial infarction (1) } \\
\text { Hemopericardium (1) } \\
\text { Atrial fibrillation }\end{array}$ & $\begin{array}{l}\text { Myocardial infarction (1) } \\
\text { Pulmonary embolism (1) } \\
\text { Superior vena cava syndrome (1) } \\
\text { Atrial fibrillation }\end{array}$ & Myocardial infarction (1) & $\begin{array}{c}\text { Myocardial infarction (1) } \\
\text { Inferior vena cava avulsion (1) } \\
\text { Hemorrhage of the right atrium (1) }\end{array}$ \\
\hline \multicolumn{4}{|c|}{ Gastro-intestinal } \\
\hline $\begin{array}{c}\text { Oesophageal perforation (2) } \\
\text { Colonic perforation (1) } \\
\text { Gastro intestinal hemorrhage (1) }\end{array}$ & $\begin{array}{c}\text { Oesophageal perforation (2) } \\
\text { Splenic rupture (1) }\end{array}$ & Oesophageal fistula (1) & \\
\hline \multicolumn{4}{|c|}{ Others } \\
\hline $\begin{array}{c}\text { Spinal cord infarction (1) } \\
\text { Chyle leak (1) }\end{array}$ & $\begin{array}{c}\text { Cerebrovascular accident (1) } \\
\text { Chyle leak (2) }\end{array}$ & $\begin{array}{c}\text { Systemic capillary } \\
\text { syndrome (2) }\end{array}$ & \\
\hline \multicolumn{4}{|c|}{ Photosensitivity } \\
\hline Skin burn, necrosis (4) & Skin burn, necrosis (1) & & \\
\hline
\end{tabular}




\section{FIGURE LEGENDS}

Figure 1: Photochemical reaction of photodynamic therapy 


\section{Abbreviations}

MPM = malignant pleural mesothelioma

$\mathrm{EPP}=$ extrapleural pneumonectomy

$\mathrm{P} / \mathrm{D}=$ pleurectomy decortication

$\mathrm{P} / \mathrm{L}=$ pleurectomy and lobectomy

PDT $=$ photodynamic therapy

PS = photosensitizer

$\mathrm{m}$-THPC $=\mathrm{m}$-tetrahydroxyphenylchlorin

DLI = drug light interval

DFS $=$ disease free survival

$\mathrm{OS}=$ overall survival 